\title{
Structure-activity relationships of 11 new congeners of the SMTP plasminogen modulator
}

\author{
Keiko Hasegawa, Haruki Koide, Weimin Hu, Naoko Nishimura, Ritsuko Narasaki, Yoshikazu Kitano \\ and Keiji Hasumi
}

The fungal metabolite Stachybotrys microspora triprenyl phenols (SMTPs) are small-molecule plasminogen modulators that enhance plasminogen activation. The SMTP molecule consists of a tricyclic $\gamma$-lactam moiety, an isoprene side-chain and an $\mathbf{N}$-linked side-chain. Previous investigations have demonstrated that the $\mathbf{N}$-linked side-chain is crucial for its activity. In this study, we have isolated 11 new SMTP congeners with a variety of $N$-linked side-chain structures, to investigate structure-activity relationships. Active compounds included congeners with a carboxyl or a sulfonic acid group in the $\mathbf{N}$-linked side-chain, whereas not all the congeners with a carboxyl group were active. Of these congeners, that with methionine or tyrosine as the $\mathbf{N}$-linked side-chain moiety was more active than that with an aliphatic amino acid. Congeners without ionizable group in the $\mathbf{N}$-linked side-chain were essentially inactive. The Journal of Antibiotics (2010) 63, 589-593; doi:10.1038/ja.2010.101; published online 15 September 2010

Keywords: fibrinolysis; plasminogen modulator; structure-activity relationships

\section{INTRODUCTION}

The plasminogen/plasmin system has a central role in blood clot lysis. ${ }^{1}$ The system is also important in other pathophysiological events, where localized proteolysis is involved. ${ }^{2-4}$ Plasminogen consists of an $\mathrm{N}$-terminal peptide, five kringle domains and a serine protease domain. ${ }^{5}$ It is proteolytically activated to plasmin by plasminogen activators through specific cleavage at $\mathrm{Arg}^{561}-\mathrm{Val}^{562} .{ }^{1}$ Plasminogen adopts tight conformation because of the intramolecular binding of Lys $^{50}$ and/or Lys ${ }^{62}$ to the lysine binding site in the fifth kringle domain. ${ }^{6,7}$ The tight conformation renders plasminogen less sensitive to activation by plasminogen activators. Plasminogen binding to fibrin or cellular receptors allows relaxation of plasminogen conformation, enabling efficient activation. This mechanism facilitates localized activation of plasminogen and following extracellular proteolysis. ${ }^{8,9}$

SMTPs are triprenyl phenol metabolites from the fungus Stachybotrys microspora. ${ }^{10-16}$ SMTP enhances both activation and fibrin binding of plasminogen by modulating plasminogen conformation, ${ }^{12-14,17,18}$ and one of the SMTP congeners is effective in treating thrombotic stroke. ${ }^{19,20}$ The SMTP molecule consists of a tricyclic $\gamma$-lactam moiety, an isoprene side-chain and an $N$-linked side-chain. Our previous studies identified 15 SMTP congeners, including staplabin and the 'D-series' stereoisomers. ${ }^{10,11,13-16}$ Except SMTP-2, which has a hydroxylated isoprene side-chain, ${ }^{11}$ the remaining congeners differ in the $\mathrm{N}$-linked side-chain moiety. Previous studies using these congeners have demonstrated that the $N$-linked side-chain is essential for the SMTP activity. SMTP-0, which lacks the $N$-linked side-chain, is inactive in promoting plasminogen activation. ${ }^{16}$ To investigate detailed structure-activity relationships, we isolated 11 new SMTP congeners with a variety of $N$-linked side-chain structures. This paper deals with the isolation and characterization of these congeners.

\section{MATERIALS AND METHODS}

Human native plasminogen (Glu ${ }^{1}$-plasminogen) was isolated on lysine-Sepharose affinity chromatography. H-Val-Leu-Lys-p-nitroanilide, a chromogenic substrate for plasmin, was obtained from Bachem (Bubendorf, Switzerland). Two-chain urokinase-type plasminogen activator was purchased from JCR Pharmaceuticals (Kobe, Japan). SMTP-4 and SMTP-6 were prepared as described previously. ${ }^{13}$ SMTP-4 methy ester (SMTP-4Me) was produced according to the method described below using L-phenylalanine methyl ester as a feeding amine. SMTP congeners with a side-chain containing carboxyl or sulfonic acid group was converted to sodium salt before assay for plasminogen activation.

Production and isolation of new SMTP congeners

S. microspora IFO 30018 was incubated at $25^{\circ} \mathrm{C}$ for 4 days in a $500-\mathrm{ml}$ Erlenmeyer flask containing $100 \mathrm{ml}$ of the seed medium consisting of glucose $(4 \%)$, soybean meal $(0.5 \%)$, peptone $(0.3 \%)$, yeast extract $(0.3 \%)$ and the antifoam CB442 (NOF Corporation, Tokyo, Japan) (0.01\%), pH 5.8. Aliquot of the seed culture $(5 \mathrm{ml})$ was transferred to a $500-\mathrm{ml}$ Erlenmeyer flask containing $100 \mathrm{ml}$ of the production medium consisting of sucrose (5\%), yeast extract $(0.1 \%), \mathrm{KNO}_{3}(0.7 \%), \mathrm{K}_{2} \mathrm{HPO}_{4}(1.5 \%), \mathrm{MgSO}_{4} \cdot 7 \mathrm{H}_{2} \mathrm{O}(0.05 \%), \mathrm{KCl}(0.05 \%)$, $\mathrm{CoCl}_{2} \cdot 6 \mathrm{H}_{2} \mathrm{O}(0.00025 \%), \mathrm{FeSO}_{4} \cdot 7 \mathrm{H}_{2} \mathrm{O}(0.0015 \%), \mathrm{CaCl}_{2} \cdot 2 \mathrm{H}_{2} \mathrm{O}(0.00065 \%)$ and $\mathrm{CB} 442(0.01 \%), \mathrm{pH} 5.8$. Flasks were incubated at $25^{\circ} \mathrm{C}$ on a rotary shaker at 180 r.p.m. After $96 \mathrm{~h}, 100 \mathrm{mg}$ of organic amine (see Table 1) was added, and the flask was incubated further for $40 \mathrm{~h}$.

The culture was mixed with $200 \mathrm{ml}$ of $\mathrm{MeOH}$, and the mixture was filtered and concentrated to remove $\mathrm{MeOH}$. After adjusting $\mathrm{pH}$ to 2 with phosphoric acid, the concentrate was settled overnight at $4{ }^{\circ} \mathrm{C}$. Precipitates formed were 
Table 1 Amine used for the production, HPLC analysis and yield of new SMTP congeners

\begin{tabular}{|c|c|c|c|c|}
\hline \multirow[b]{2}{*}{ Compound } & \multirow[b]{2}{*}{ Amine added } & \multicolumn{2}{|c|}{$H P L C$} & \multirow[b]{2}{*}{ Yield $\left(m g l^{-1}\right)$} \\
\hline & & Solventa & $t_{R}(\min )$ & \\
\hline SMTP-10 & L-isoleucine & $80 \% \mathrm{MeOH}$ & 11.4 & 535 \\
\hline SMTP-11 & L-valine & $70 \% \mathrm{MeOH}$ & 15.6 & 480 \\
\hline SMTP-12 & L-alanine & $70 \% \mathrm{MeOH}$ & 13.4 & 1074 \\
\hline SMTP-13 & L-methionine & $70 \% \mathrm{MeOH}$ & 17.5 & 768 \\
\hline SMTP-14 & L-tyrosine & $70 \% \mathrm{MeOH}$ & 11.2 & 92 \\
\hline SMTP-15 & L-arginine & $70 \% \mathrm{MeOH}$ & 13.2 & 369 \\
\hline SMTP-16 & 1-Naphthylamine & $100 \% \mathrm{MeOH}$ & 12.0 & 2304 \\
\hline SMTP-33 & D-(+)-glucosamine & $75 \% \mathrm{MeOH}$ & 9.4 & 324 \\
\hline SMTP-38 & 4-Aminoantipyrine & $75 \% \mathrm{MeOH}$ & 17.6 & 458 \\
\hline SMTP-40 & 4-Amino- $n$-butanoic acid & $75 \% \mathrm{MeOH}$ & 9.5 & 130 \\
\hline SMTP-42 & $p$-Sulfanilic acid & $75 \% \mathrm{MeOH}$ & 10.7 & 123 \\
\hline
\end{tabular}

Abbreviation: HPLC, high-performance liquid chromatography; SMTP, S. microspora triprenyl phenol. ${ }^{a}$ All solvents contained $50 \mathrm{~mm}$ ammonium acetate except that for SMTP-16.

collected by centrifugation and dissolved in acetone. After evaporation, the resulting oily residue was dissolved in $\mathrm{MeOH}$, treated with Lichrolut RP-18 (Merck, Darmstadt, Germany), and subjected to preparative high-performance liquid chromatography on an Inertsil PREP-ODS $(30 \times 250 \mathrm{~mm}$; GL Science, Tokyo, Japan). The column was developed at a rate of $25 \mathrm{ml}$ per minute at $40{ }^{\circ} \mathrm{C}$ with a solvent mixture shown in Table 1. Fractions containing desired compound were evaporated to remove $\mathrm{MeOH}$. Purified materials were obtained after ethyl acetate extraction (for ammonium acetate-containing solvent) or direct evaporation (for $\mathrm{MeOH}$ solvent). The yield of each congener is shown in Table 1.

\section{Assay for plasminogen activation}

The activation of plasminogen was assayed by measuring initial velocity for urokinase-type plasminogen activator-catalyzed plasmin generation using the chromogenic substrate $\mathrm{H}$-Val-Leu-Lys-p-nitroanilide. A reaction mixture consisting of $50 \mathrm{nM}$ plasminogen, $50 \mathrm{U} \mathrm{ml}^{-1}$ urokinase-type plasminogen activator and $0.1 \mathrm{~mm}$ $\mathrm{H}$-Val-Leu-Lys- $p$-nitroanilide in $50 \mu \mathrm{l}$ of buffer $(50 \mathrm{~mm}$ Tris- $\mathrm{HCl}, 100 \mathrm{~mm} \mathrm{NaCl}$ and $0.01 \%$ Tween $80, \mathrm{pH} 7.4$ ) was incubated in the presence or absence of SMTP congeners at $37^{\circ} \mathrm{C}$. The hydrolysis of H-Val-Leu-Lys-p-nitroanilide (absorbance at $405 \mathrm{~nm}$ ) was kinetically monitored for up to $60 \mathrm{~min}$. From the slope of the plots of $\mathrm{A}_{405}$ versus $t^{2}$, the initial velocity of plasmin generation was calculated.

\section{General procedures}

Ultraviolet spectrum was measured in $\mathrm{MeOH}$ on a model 320 spectrometer (Hitachi, Tokyo, Japan) and IR spectrum on a JIR-WINSPEC (Jeol, Tokyo, Japan) with $\mathrm{NaCl}$. Matrix-assisted laser desorption/ionization time-of-flight mass spectrometry (MALDI-TOF-MS) spectrum was taken on a Voyager DE STR (Applied Biosystem, CA, USA) using $\alpha$-cyano-4-hydroxycinnamic acid as a matrix. nuclear magnetic resonance spectra were measured in dimethylsulfoxide (DMSO)- $d_{6}$ or acetone- $d_{6}$ on a JNM- $\alpha-600$ (Jeol). Optical rotation was measured in $\mathrm{MeOH}$ on a model DIP-360 (Jasco, Tokyo, Japan).

\section{RESULTS AND DISCUSSION}

Isolation and physico-chemical properties of new SMTP congeners Our previous studies established that, in S. microspora cultures, the precursor amine feeding selectively enhanced the production of particular SMTP of interest. ${ }^{15,21}$ The fermentation conditions for the SMTP production have been improved significantly. ${ }^{16}$ On the basis of these methods, we produced 11 new SMTP congeners with a variety of $\mathrm{N}$-linked side-chain structures to investigate detailed structure-activity relationships with respect to plasminogen activation. Congeners were isolated on preparative high-performance liquid chromatography. The fed amines, analytical high-performance liquid chromatography conditions and yields of new congeners are summarized in Table 1.
Previous studies have demonstrated that the fed amine was introduced as the $N$-linked side-chain of the SMTP molecule. ${ }^{15,16,21}$ The physico-chemical properties of new SMTP congeners (Table 2) were consistent with this notion. The nuclear magnetic resonance analysis supported this conclusion (see Supplementary Figures S1-S11). Thus, the structure of the new SMTP congeners was identified as shown in Figure 1.

SMTP-33, which was produced by feeding D-glucosamine, seemed to be an anomeric mixture. Many of its carbon signals accompanied signals that were $\sim 1 / 3$ the intensity of adjacent signals in the ${ }^{13} \mathrm{C}$ nuclear magnetic resonance spectrum (see Supplementary Figure S8B). Major signals could be assigned as those of $\alpha$-anomer from chemical shift values (minor signals are shown in the note for Table 2). Anomerization can occur readily in aqueous solutions, leading to anomeric equilibrium. Therefore, we regard SMTP-33 a single compound in the evaluation of its effect on plasminogen activation, which is to be assessed in aqueous buffer solution.

\section{Structure-activity relationships of the SMTP congeners}

Previously identified SMTP congeners are roughly divided into two groups: one is the single-unit congener, most of which has an amino acid as an $\mathrm{N}$-linked side-chain, and the other is the two-unit congener, which has two core SMTP structures bridged by diamine compounds, such as ornithine and lysine. ${ }^{14,15}$ Of the single-unit congeners, compounds without ionizable group in the $N$-linked side-chain (SMTP-0 and SMTP-1) are inactive. ${ }^{11,16}$ (Ionizability is estimated from compound's pKa value (calculated using ALOGPS 2.1 program; http://www.vcclab. org/lab/alogps/22 and $\mathrm{pH}$ of buffer used for assay ( $\mathrm{pH} 7.4$ ).) To test for the role of an ionizable group in the side-chain, we first compared the activity of SMTP-4 with methyl SMTP-4 (SMTP-4Me). The result showed that the ester was essentially inactive (Figure 2). In addition, other congeners without ionizable group in the side-chain were also inactive, whether the side-chain was hydrophilic (SMTP-33) or hydrophobic (SMTP-16 and -38). Moreover, the congener with both positively and negatively ionizable groups (SMTP-15) was inactive.

Active compounds included congeners with a carboxyl or a sulfonic acid group in the $\mathrm{N}$-linked side-chain, whereas not all the congeners with a carboxyl group were active (Figure 2). Of these congeners, SMTP- 12 and -40 , which had alanine and 4 -amino- $n$-butanoic acid, respectively, as the side-chain moiety, were inactive. SMTP-10 and -11, which had isoleucine and valine, respectively, as the side-chain, showed weak activity $\left(\mathrm{E}_{\max } / \mathrm{EC}_{10}=0.04\right.$ and 0.03 fold $\mu \mathrm{M}^{-1}$, respectively) (see legend to Figure 2 for definitions of $\mathrm{EC}_{10}$ and $\mathrm{E}_{\max }$ ). Thus bulkiness of the side-chain may slightly contribute to activity of a congener with an aliphatic carboxyl group. On the other hand, SMTP$13\left(\mathrm{E}_{\mathrm{max}} / \mathrm{EC}_{10}=0.27\right.$ fold $\left.\mu \mathrm{M}^{-1}\right)$, which had methionine as the sidechain moiety, was more active than SMTP-10. The marked difference between SMTP-13 and SMTP-10 is the presence of divalent sulfur in the side-chain of SMTP-13. The divalent sulfur in methionine participates in non-hydrogen bond interactions with an oxygen atom or an aromatic ring by behaving as an electrophile. ${ }^{23,24}$ Such interactions are thought to be important in the stabilization of protein folding and molecular recognition. Although it needs additional investigation to understand the mechanism, there is a possibility that the divalent sulfur in SMTP-13 may have a particular role in the interaction with plasminogen. Other active congeners were SMTP14 (with tyrosine as the side-chain) $\left(\mathrm{E}_{\max } / \mathrm{EC}_{10}=0.99\right.$ fold $\left.\mu \mathrm{M}^{-1}\right)$ and SMTP-42 (with $p$-sulfanilic acid as the side-chain) $\left(\mathrm{E}_{\max } / \mathrm{EC}_{10}=0.44\right.$ fold $\mu \mathrm{M}^{-1}$ ). Their activities were higher than that of SMTP-6 (with tryptophan as the side-chain) $\left(\mathrm{E}_{\max } / \mathrm{EC}_{10}=0.27\right.$ fold $\left.\mu \mathrm{M}^{-1}\right)$, which was most active among previously isolated single-unit SMTP. 


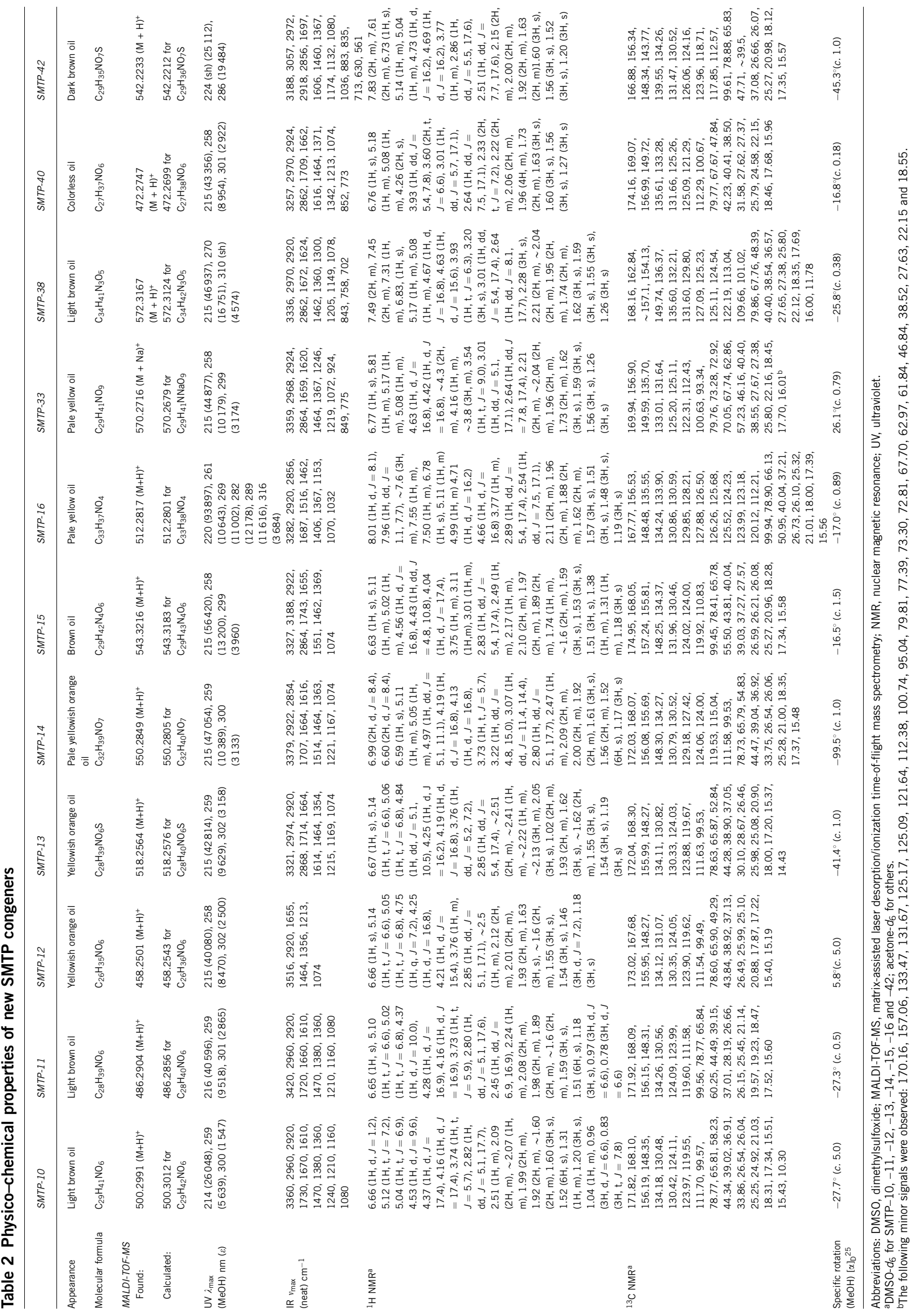




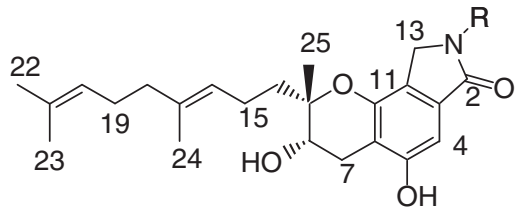

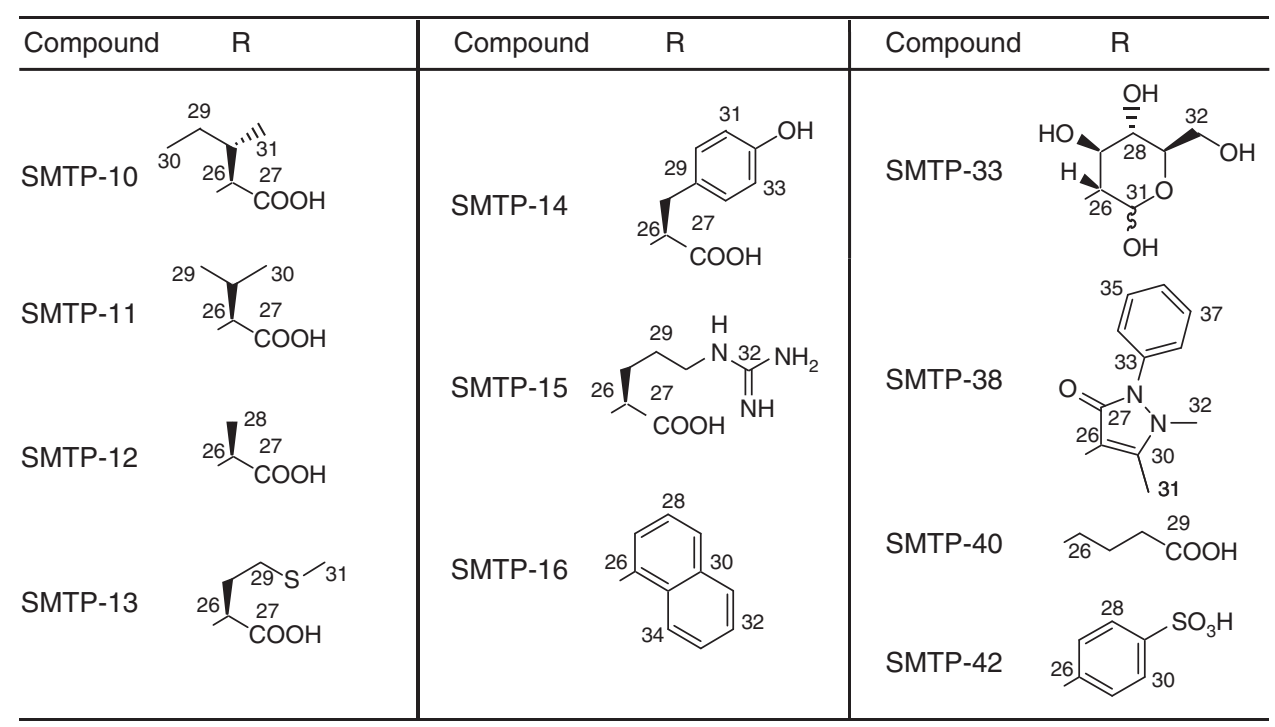

Figure 1 Structures of the new SMTP congeners.

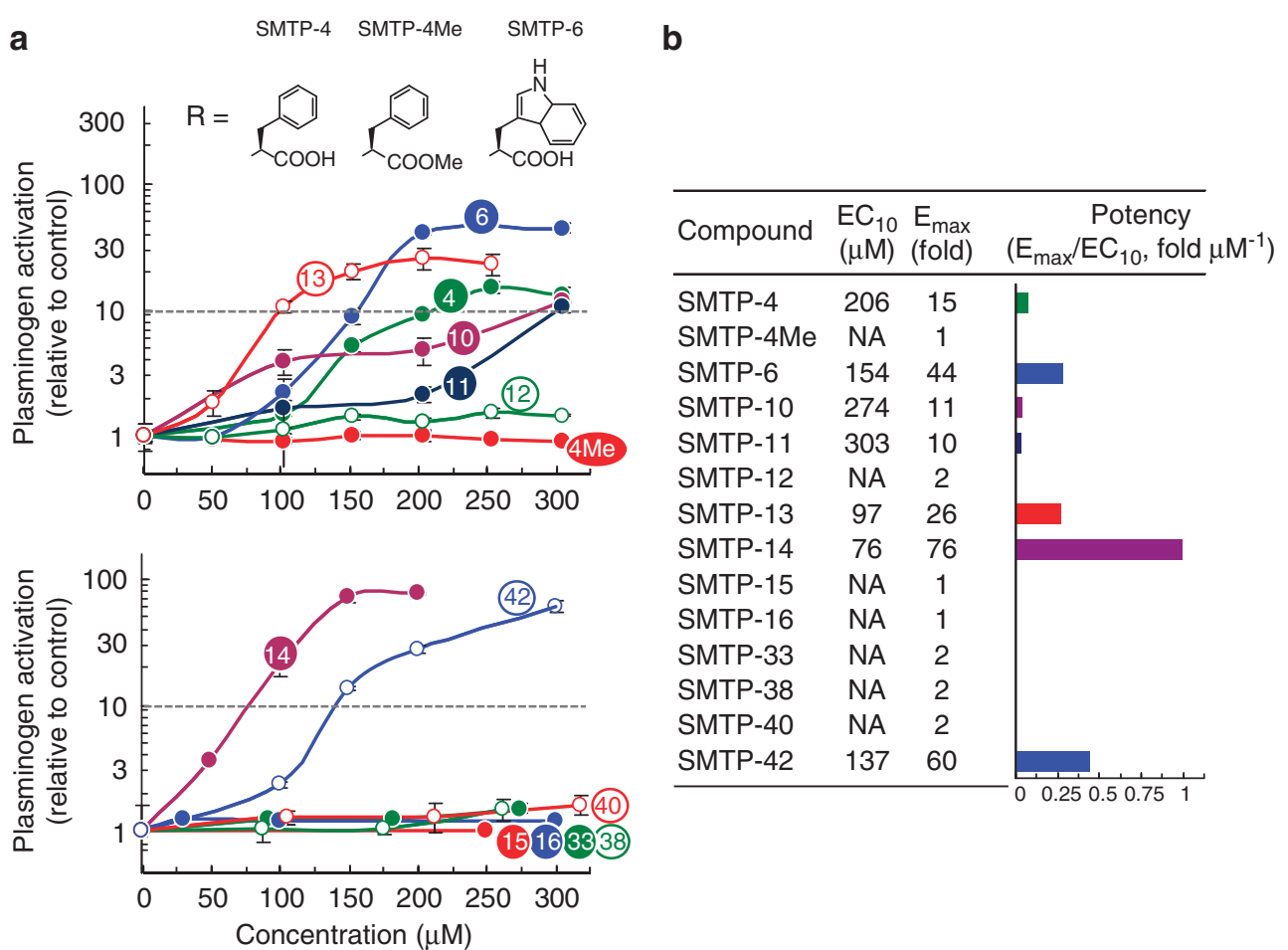

Figure 2 Structure-activity relationships of the new SMTP congeners. (a) The activation of plasminogen was assayed in the presence of the indicated concentrations of each SMTP congener. Numbers in circle represent the SMTP number. The $N$-linked side-chain structures for SMTP-4, $-4 M e$ and -6 are shown. Each value represents the mean \pm s.d. from triplicate determinations. The mean control value obtained from nine experiments was $5.80 \pm 1.88 \mathrm{~nm}$ plasmin generated per hour. Percent of control values are shown. (b) Summary of the results in panel (a). EC ${ }_{10}$, concentration ( $\mu \mathrm{m}$ ) of SMTP that causes 10 fold enhancement of plasminogen activation; $E_{\max }$, maximum level of enhancement (fold increase in plasminogen activation compared with control). $E_{\max }$ and the reciprocal of $\mathrm{EC}_{10}$ are independent indexes that represent the potency of the compound tested. The ratio $E_{\max } / \mathrm{EC}_{10}$ is introduced to represent comprehensive potency. NA, not available (due to that enhancement did not reach 10 fold at concentrations tested). 
Taken together, it is likely that an SMTP congener without ionizable group in the $N$-linked side-chain is inactive in spite of the fact that the side-chain is hydrophobic or hydrophilic. The presence of negatively ionizable group in the side-chain may be required, but not satisfactory to an active congener. A congener both with an aromatic group and a negatively ionizable group in the side-chain is more active than a congener with an aliphatic group and a negatively ionizable group. Divalent sulfur in the side-chain may contribute to activity.

\section{ACKNOWLEDGEMENTS}

We thank Dr Hiroshi Hara (Tokyo University of Pharmacy and Life Sciences) for discussion. Human plasma for plasminogen isolation was provided by the Japanese Red Cross Society, Tachikawa. This work was supported in part by grant from the Japan Society for the Promotion of Science.

1 Rijken, D. C. \& Lijnen, H. R. New insights into the molecular mechanisms of the fibrinolytic system. J. Thromb. Haemost. 7, 4-13 (2008).

2 Lund, L. R. et al. Plasminogen activation independent of UPA and TPA maintains wound healing in gene-deficient mice. EMBO J. 25, 2686-2697 (2006).

3 Danø, K. et al. Plasminogen activation and cancer. Thromb. Haemost. 93, 676-681 (2005).

4 Boyle, M. D. \& Lottenberg, R. Plasminogen activation by invasive human pathogens. Thromb. Haemost. 77, 1-10 (1997).

5 Forsgren, M., Raden, B., Israelsson, M., Larsson, K. \& Heden, L.-O. Molecular cloning and characterization of a full-length cDNA clone for human plasminogen. FEBS Lett. 213, 254-260 (1987).

6 Cockell, C. S., Marshall, J. M., Dawson, K. M., Cederholm-Williams, S. A. \& Ponting, C. $P$. Evidence that the conformation of unliganded human plasminogen is maintained via an intramolecular interaction between the lysine-binding site of kringle 5 and the $\mathrm{N}$ terminal peptide. Biochem. J. 333, 99-105 (1998).

7 An, S. S., Carreño, C., Marti, D. N., Schaller, J., Alberico, F. \& Llinas, M. Lysine-50 is a likely site for anchoring the plasminogen $\mathrm{N}$-terminal peptide to lysine-binding kringles. Protein Sci. 7, 1960-1969 (1998).

8 Nesheim, M. E., Fredenburgh, J. C. \& Larsen, G. R. The dissociation constants and stoichiometries of the interactions of Lys-plasminogen and chloromethyl ketone derivatives of tissue plasminogen activator and the variant $\Delta \mathrm{FEIX}$ with intact fibrin. J. Biol. Chem. 265, 21541-21548 (1990).
9 Hajjar, K. A. \& Nacman, R. L. Endothelial cell-mediated conversion of Glu-plasminogen to Lys-plasminogen. Further evidence for assembly of the fibrinolytic system on the endothelial cell surface. J. Clin. Invest. 82, 1769-1778 (1988).

10 Shinohara, C., Hasumi, K., Hatsumi, W. \& Endo, A. Staplabin, a novel fungal triprenyl phenol which stimulates the binding of plasminogen to fibrin and U937 cells. J. Antibiot. 49, 961-966 (1996).

11 Kohyama, T., Hasumi, K., Hamanaka, A. \& Endo, A. SMTP-1 and -2, novel analogs of staplabin produced by Stachybotrys microspora IFO30018. J. Antibiot. 50, 172-174 (1997).

12 Takayasu, R., Hasumi, K., Shinohara, C. \& Endo, A. Enhancement of fibrin binding and activation of plasminogen by staplabin through induction of a conformational change in plasminogen. FEBS Lett. 418, 58-62 (1997).

13 Hasumi, K., Ohyama, S., Kohyama, T., Ohsaki, Y., Takayasu, R. \& Endo, A. Isolation of SMTP-3, $-4,-5$ and -6 , novel analogs of staplabin, and their effects on plasminogen activation and fibrinolysis. J. Antibiot. 51, 1059-1068 (1998).

$14 \mathrm{Hu}$, W., Ohyama, S. \& Hasumi, K. Activation of fibrinolysis by SMTP-7 and -8, novel staplabin analogs with a pseudosymmetric structure. J. Antibiot. 53, 241-247 (2000).

$15 \mathrm{Hu}$, W., Kitano, Y. \& Hasumi, K. SMTP-4D, -5D, -6D, -7D and -8D, a new series of the non-lysine-analog plasminogen modulators with a D-amino acid moiety. J. Antibiot. 56, 832-837 (2003).

16 Hasumi, K., Hasegawa, K. \& Kitano, Y. Isolation and absolute configuration of SMTP-0, a simplest congener of the SMTP family nonlysine-analog plasminogen modulators. J. Antibiot. 60, 463-468 (2007).

17 Ohyama, S., Harada, T., Chikanishi, T., Miura, Y. \& Hasumi, K. Nonlysine-analog plasminogen modulators promote autocatalytic generation of plasmin(ogen) fragments with angiostatin-like activity. Eur. J. Biochem. 271, 809-820 (2004).

18 Hasumi, K., Yamamichi, S. \& Harada, T. Small molecule modulators of the zymogen activation in the fibrinolytic and coagulation systems. FEBS J. 277, 3675-3687 (2010).

19 Shibata, K, Hashimoto, T, Nobe, K, Hasumi, K \& Honda, K A novel finding of a lowmolecular-weight compound, SMTP-7, having thrombolytic and anti-inflammatory effects in cerebral infarction of mice. N.-S. Arch. Pharmacol. 382, 245-253 (2010).

20 Hashimoto, T., Shibata, K., Nobe, K., Hasumi, K. \& Honda, K. A novel embolic mode of cerebral infarction and evaluation of SMTP-7, a novel fungal triprenyl phenol metabolite. J. Pharmacol. Sci. (doi:10.1254/jphs.10131FP) (2010).

$21 \mathrm{Hu}$, W., Ohyama, S., Narasaki, R. \& Hasumi, K. Selective production of staplabin and SMTPs in cultures of Stachybotrysmicrospora fed with precursor amines. J. Antibiot. 54, 962-966 (2001).

22 Tetko, I. V. \& Poda, G. I. Application of ALOGPS 2.1 to predict log D distribution coefficient for Pfizer proprietary compounds. J. Med. Chem. 47, 5601-5604 (2004).

$23 \mathrm{Pal}$, D. \& Chakrabarti, P. Non-hydrogen bond interactions involving the methionine sulfur atom. J. Biomol. Struct. Dyn. 19, 115-128 (2001).

24 Chakrabarti, P. \& Bhattacharyya, R. Geometry of nonbonded interactions involving planar groups in proteins. Prog. Biophys. Mol. Biol. 95, 83-137 (2007).

Supplementary Information accompanies the paper on The Journal of Antibiotics website (http://www.nature.com/ja) 